The University of Maine

DigitalCommons@UMaine

Publications

Senator George J. Mitchell Center for Sustainability

Solutions

6-2014

\title{
Collaborative Voice: Examining the Role of Voice in Interdisciplinary Collaboration
}

Brandon J. Cosley

University of South Carolina - Beaufort

Shannon McCoy

University of Maine, shannon.mccoy@maine.edu

Susan Gardner

University of Maine, susan.gardner@maine.edu

Follow this and additional works at: https://digitalcommons.library.umaine.edu/ mitchellcenter_pubs

Part of the Organizational Communication Commons

\section{Repository Citation}

Cosley, Brandon J.; McCoy, Shannon; and Gardner, Susan, "Collaborative Voice: Examining the Role of Voice in Interdisciplinary Collaboration" (2014). Publications. 113.

https://digitalcommons.library.umaine.edu/mitchellcenter_pubs/113

This Article is brought to you for free and open access by DigitalCommons@UMaine. It has been accepted for inclusion in Publications by an authorized administrator of DigitalCommons@UMaine. For more information, please contact um.library.technical.services@maine.edu. 
INTERNATIONAL JOURNAL OF ORGANIZATION THEORY AND BEHAVIOR, 17 (2), 139-162 S SUMMER 2014

\title{
COLLABORATIVE VOICE: EXAMINING THE ROLE OF VOICE IN INTERDISCIPLINARY COLLABORATION
}

\author{
Brandon J. Cosley, Shannon K. McCoy and Susan K. Gardner*
}

\begin{abstract}
The present study examined the role of voice in facilitating interdisciplinary collaboration. According to the group-value model of procedural justice, voice relates to interpersonal relationships among coworkers because it facilitates a greater interest in helping the group (e.g. group-serving behavior). We argue that because of the relationship between voice and one type of group-serving behavior--advice sharing--that greater perceptions of voice would also predict more collaboration. In a field study examining collaborative social networks among university researchers, we found that greater perceptions of voice positively related to both degree of advice sharing and collaboration. Moreover, the extent to which individuals shared advice fully mediated the relationship between perceived voice and collaboration. Implications for voice and collaboration are discussed.
\end{abstract}

\section{INTRODUCTION}

The world is facing problems that are so complex that no single academic discipline can expect to solve them effectively (e.g. Ewel, 2001; Holley, 2009). This complexity in modern problems is driven by our connectedness to information exposing us to interdisciplinary perspectives with the mere click of a button. Thus, collaboration among colleagues across disciplines is essential to developing innovative solutions for incorporating complexity in the problems we

* Brandon J. Cosley, Ph.D., is Assistant Professor of Psychology, Department of Social Sciences, University of South Carolina at Beaufort. His research interests focus on stress and system sustainability. Shannon K. McCoy, Ph. D., is an Assistant Professor, Department of Psychology, University of Maine. Her research examines the role of stress in well-being and interdisciplinary collaboration. Susan K. Gardner, Ph.D., is Associate Professor of Higher Education and Director of the NSF ADVANCE Rising Tide Center, University of Maine. Her research interests focus on the intersections of individual development in organizational cultures.

Copyright $\odot 2014$ by Pracademics Press 
face (Cummings \& Kiesler, 2005; Zare, 1997). Unfortunately, engaging in interdisciplinary collaboration has been contrary to the historical development of disciplines in academia, which focus more on specialization than on integration (Schein, 1972). Moreover, because collaboration involves relationships with others, the challenges of collaboration often manifest themselves through interpersonal tensions. Therefore, identifying ways to improve interdisciplinary collaboration among colleagues is necessary to effectively addressing modern problems.

The National Science Foundation defines interdisciplinary collaboration as "a mode of research by teams or individuals that integrates information, data, techniques, tools, perspectives, concepts, and/or theories from two or more disciplines or bodies of specialized knowledge to advance fundamental understanding or to solve problems whose solutions are beyond the scope of a single discipline or area of research practice" (National Research Council, 2004 , p. 2). In the present research, we apply this notion of interdisciplinary collaboration to the broader context of organizational behavior and examine how one important variable in organizational effectiveness--voice--impacts collaboration. Following Lind and Tyler's (1988) group-value model of procedural justice, having voice (e.g. input into organizational decisions) influences how employees relate to one another (e.g. Cornelis, Van Hiel, \& De Cremer, 2006; LePine \& Van Dyne, 2001). The group-value model proposes and research supports that having more voice leads to greater engagement in behaviors aimed at helping the group (e.g. group-serving behaviors). We propose that these additional interactions with colleagues open up avenues for building collaborations. In the present research we examine one specific type of group-serving behavior that is particularly likely to lead to more collaboration-advice sharing. Because collaboration requires the communication of ideas, sharing advice with colleagues presents opportunities for employees to see the value in each other's areas of expertise. Therefore, we propose that greater perceptions of voice would also be associated with greater collaboration through its relationship with advice sharing.

In the next section, we discuss the challenge associated with interdisciplinary collaboration by emphasizing the role of interpersonal relationships. We then review the theoretical and empirical background on the "voice effect" (Folger, 1977; Lind, 
Kanfer \& Earley, 1990; Avery, McKay, Wilson, Volpone, \& Killham, 2011) and highlight the importance of voice for interpersonal relationships among co-workers (Lind \& Tyler, 1988). Finally, we discuss previous work demonstrating the role of voice in improving interpersonal relationships through increasing group-serving behaviors. Based on our review of this literature, we link voice to interdisciplinary collaboration and propose that advice sharing mediates the link between voice and collaboration.

\section{BUILDING COLLABORATION THROUGH PROCEDURAL VOICE}

\section{The Challenge of Interdisciplinary Collaboration: Interpersonal} Relationships

Collaboration generally, and interdisciplinary collaboration more specifically, is arguably the new organization of modern academia. The influx of grant money has provided starving institutions with a means for survival and innovation (National Research Council, 2004) paving the way for greater interdisciplinary collaboration. Despite the many new sources of funding, interdisciplinary collaboration runs contrary to the status quo of the academic environment (Aldrich \& Ruef, 2006). Academic institutions have historically compartmentalized domains of knowledge in discrete disciplines (Newell, 2001). It is commonplace for these disciplines not only to develop their own specialized curriculum but also to house them in entirely different physical locations. Therefore, interdisciplinary collaboration arguably represents a change from these preexisting academic structures (Slatin, Galizzi, Devereaux, \& Mawn, 2004; Holley, 2009).

Most importantly, this change to the status quo also represents significant challenges to the interpersonal relationships involved in interdisciplinary collaboration (Holley, 2009). As scientists engage in collaboration even within discipline, their efforts are characterized by interpersonal tension (Hackett, 2005; Hackett, 1990; Hagstrom, 1965; Merton, 1973; Traweek, 1988). When different disciplines engage in collaborative projects these tensions are exacerbated as differences in language, methods, and tools create an environment of heightened uncertainty and ambiguity (Adamson \& Walker, 2011), increasing the potential for distress (Lopes, 1987; Van Den Bos, 2001). Thus, changing organizational environments accompanied by 
interpersonal tensions arguably have a negative impact on the building of collaborative relationships.

\section{Voice and Interpersonal Relationships}

One way to manage the interpersonal challenges of interdisciplinary collaboration may be through voice. Consistent with previous theorizing, we define voice as the perception that one has influence over the decision processes of an organization (Lind, Kanfer \& Earley, 1990). For leaders of organizations, ensuring that employees feel as though they have voice has been associated with many organizational benefits. For example, voice increases perceptions of procedural fairness (Thibaut \& Walker, 1975), employee motivation (Travis \& Mor Barak, 2010), organizational identification (Smith \& Tyler, 1997), performance (Hunton, 1996), and reduces stress (Brotheridge, 2003; Ng \& Feldman, 2012). In fact, the relationship between voice and perceptions of fairness is so robust that some have even used manipulations of voice as a proxy for manipulating procedural fairness (e.g. Cornelis, Van Hiel \& De Cremer, 2006). Initial theorizing regarding the role of voice in organizational fairness emphasized the role of control, arguing that when individuals feel in control over organizational decisions (e.g. voice) they can maximize self-interest (Thibaut \& Walker, 1975). This theory, however, fails to explain why perceptions of voice affects individuals, even when their input has no real influence on decision outcomes (e.g. McFarlin \& Sweeney, 1996; Tyler, Rasinski, \& Spodick, 1985).

According to Lind and Tyler's (1988) group-value model, voice is associated with positive organizational outcomes because it signals that employees are valued members of their organizations. Because individuals care about how they are perceived in social groups (Tajfel \& Turner, 1986), feeling as though one has a say in the decision process, regardless of any actual influence, reflects that the group respects one's opinions and thus, that one is valued. Research examining the consequences of the group-value model has supported that voice not only impacts relationships with leaders but also relationships among coworkers. For example, greater voice is associated with greater cooperation (LePine \& Van Dyne, 2001) along with more positive feelings towards coworkers (Cornelis, Van Hiel \& De Cremer, 2006). Importantly, greater perceptions of voice may improve interpersonal relationships because such perceptions also 
encourage a stronger tendency to engage in group-serving behaviors (e.g. Tyler, Degoey, \& Smith, 1996; Konovsky \& Folger, 1991; Moorman, 1991). Group-serving behaviors, also referred to as organizational citizenship behaviors, contextual performance, or extrarole behaviors in the literature (O'Reilly \& Chatman, 1986; Organ, 1988, 1997; Lepine \& Van Dyne, 2001; Borman \& Motowidlo, 1997; Ozer, 2011), are widely defined as behaviors that help other group members without any clear relevance to one's required role within an organization (e.g. Barry \& Tyler, 2009). Because these group-serving behaviors are often directed towards co-workers, not simply leaders, they also likely lead to more positive interactions among colleagues. These behaviors allow for the building of emotional bonds that may determine whether colleagues decide to work with one another (Bennett \& Kidwell, 2001). In light of the research linking greater employee voice to improved performance outcomes (e.g. Hunton, 1996); we propose that greater perceived voice would be more strongly related to substantive collaborations that represent important performance outcomes.

\section{Voice, Advice, and Collaboration}

Although there are many ways to help other group members and these various group-serving behaviors are also likely to lead to various positive effects among colleagues, not all group-serving behaviors per se should be expected to lead to greater collaboration. This may be especially true when examining collaborations that represent real performance outcomes among colleagues. Because substantive collaborations that have important consequences for performance in an interdisciplinary context requires individuals to communicate their knowledge to others so that colleagues may become aware of how their perspectives add value to solve complex problems (Boix Mansilla \& Duraising, 2007), group-serving behaviors that require colleagues to share unique knowledge should be the most likely to also promote collaboration. One type of group-serving behavior that may represent an opportunity for individuals to share their knowledge value is advice sharing. Therefore, we propose that through the sharing of advice individuals are also more likely to develop more collaboration with one another.

Just as advice sharing is likely related to collaboration, so too should it be related to perceived voice. Aside from representing one type of group-serving behavior generally, advice sharing also involves 
employees influencing one another. In this way advice sharing may be conceptualized as a type of voice-behavior. Indeed, Liu, Zhu, and Yang (2010) differentiate between two types of voice: one where individuals speak up to influence supervisors, and another that involves speaking out to influence peers. It is important to point out that we are not arguing that the only function of advice sharing is as a voice-behavior because there is extensive research on the importance of advice in its own right (e.g. Argote \& Ingram, 2000; Borgatti \& Cross, 2003; Zagenczyk \& Murrell, 2009). We are arguing, however, that because advice sharing allows employees to influence one another and may signal value and respect in much the same way that voice does, advice sharing may be one strategy through which individuals can express voice and thus we expect it to be associated with perceived voice (Avery \& Quinones, 2002).

Additional evidence that advice sharing may in part signal one type of voice behavior comes from an examination of the similarity in advice and voice effects. For example, transformational leadership has been associated with both increases in voice (e.g. Conchie, Taylor, \& Donald, 2012; Liu, Zhu \& Yang, 2010) as well as fostering greater connections in advice networks (e.g. Zhang \& Peterson, 2011). Greater engagement in advice sharing relates to increases in job identification (Zagenczyk \& Murrell, 2009) as are greater perceptions of voice (e.g. Smith \& Tyler, 1997). Therefore, we argue that because advice sharing is both a group-serving behavior as well as a way employees may influence their organizations, greater perceptions of voice should be positively associated with advice sharing.

In further support of advice sharing's unique role, we include an additional group-serving type of behavior in our study. Choosing to serve on committees is a group-serving behavior in that the intent of committees is to improve group outcomes. It is different, however, from advice sharing in that individuals who serve on committees are not given opportunities to express their unique perspectives for solving research problems. Thus, we expect to demonstrate that only the group-serving behavior of advice sharing will successfully explain the link between perceived voice and substantive collaborations, not the extent to which individuals serve on the same committees together. 


\section{THE PRESENT RESEARCH}

\section{Hypotheses and Study Overview}

Although it may be commonly assumed that perceived voice ought to share a relationship with substantive collaborations (e.g. Rank, Pace and Frese (2004); Franco et al. (2007), this assumption has never been empirically tested. In the present work, we directly test the hypothesis that perceived voice is positively associated with actual collaborations. Thus, this work represents the first empirical investigation attempting to link perceived voice to interdisciplinary collaboration in an academic organization. Moreover, we examine the uniqueness of voice in predicting collaborative behavior by examining the role of other variables also commonly assumed important for formation of collaborations. Interest in collaboration (Tompkins, Weaver, \& Landers, 1989; National Research Council, 2004) and receiving credit for collaborative efforts (Mellin \& Winton, 2003; Slatin et al., 2004; National Research Council, 2004) have been argued as important individual-level variables that facilitate interdisciplinary collaborations. We examine each of these variables in relation to the forms of collaboration examined in the present study in order to understand more completely the role of perceived voice in the context of other arguably important variables.

In this research we take a multi-method approach (i.e. surveys and social networks) to examine the relationship between perceived voice, advice networks, and collaboration networks. The use of social network methods allows us to examine reports of actual relationships imbedded among other possible relationships. This is particularly advantageous when examining weighted networks (as our collaboration network is) where individuals connect more strongly through multiple collaborations. The social network approach allows us to quantify how involved individuals are in the networks. Based on our review of the literature regarding the group-value of voice and its effects on interpersonal relationships, we specifically test the following three hypotheses (Figure 1):

Hypothesis 1: Greater perceptions of voice will be positively associated with a greater number of collaborations.

Hypothesis 2: Greater perceptions of voice will be positively associated with a greater number of advice ties. 
Hypothesis 3: The extent to which advice is given will mediate the relationship between perceptions of voice and collaborative relationships.

FIGURE 1

Theoretical Model of Relationships among Perceived Voice, Advice Network, and Collaboration Network

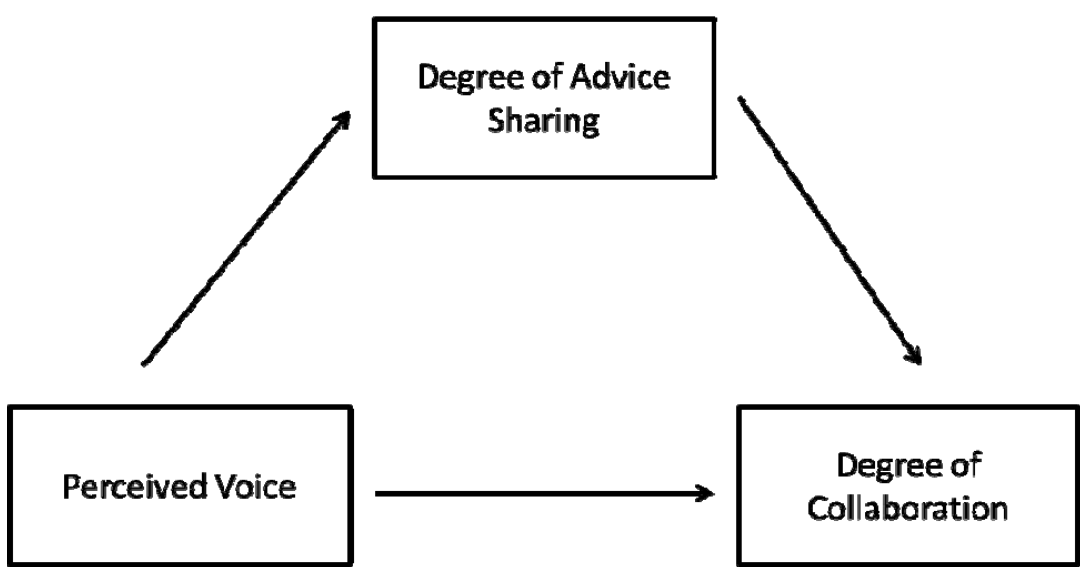

Interdisciplinary Collaboration in the Sustainability Solutions Initiative (SSI)

The present research was carried out in an applied work setting using participants from an interdisciplinary initiative on the campus of the University of Maine in Orono, ME. In 2010, the University of Maine was awarded a five-year EPSCoR grant from the National Science Foundation to engage in a research initiative promoting an interdisciplinary understanding to the problem of environmental sustainability. Prior to the receipt of grant funds for the Sustainability Solutions Initiative, researchers on campus formed interdisciplinary relationships. Therefore, the present sample represents a unique time during initial project development that was rich with collaboration. 
COLLABORATIVE VOICE: EXAMINING THE ROLE OF VOICE IN INTERDISCIPLINARY COLLABORATION 147

\section{METHOD}

\section{Participants}

Participants were 27 faculty (Female $=10$, Male $=17$ ) involved in the early formation of the Sustainability Solutions Initiative. Participants represented over 10 different academic disciplines (e.g. human services, ecology, communications, and chemistry). In addition, 5 participants were assistant professors, 5 were associate professors, 14 were professors, and 3 were research staff.

\section{Measures}

The survey allowed for the collection of both individual- and network-level data. Individual-level data consisted of self-report measures of perceived voice. Network-level data represent relationships of various types among each core faculty involved in the project.

Network data were measured by presenting participants with a list of all other participants involved in the sustainability solutions initiative at the time of the study and asking them to indicate their relationship with one another on a variety of dimensions. In order to quantify how connected individuals were in each network we computed degree centrality (Wasserman \& Foust, 1994; Freeman, 1977). Degree centrality is simply the number of ties an actor has with others (Freeman, 1977), standardized by dividing by the number of actors minus 1 . Because our collaboration network included collaborations of different types, we computed a weighted degree centrality score that captured the sum of the weights of all links among individuals. Overall, actors with high degree scores are more involved in the network (Knoke \& Yang 2008).

- Collaboration Network. Interdisciplinary collaboration networks were determined by asking participants to indicate whether they have collaborated with another participant in a variety of substantive contexts that have clear performance implications (e.g. written grants, co-authored papers). The collaboration network not only indicated the presence of a particular collaboration but also the frequency of collaboration among actors and constituted our primary outcome network in the study. 
- Advice Network. Our measure of advice network was based on social ties where participants had indicated sharing advice with other individuals.

- Committee Network. As an additional type of group-serving behavior, we also examined relationships based on whether participants participated in the same committees.

- Perceptions of Voice. We used a single face-valid item as our measure of perceived voice ("I feel I have input into SSI-related decisions"). The item was measured on a 1 (disagree) to 8 (agree) scale and indicates the extent to which individuals agree that they have input into the decision process.

- Interest in Collaboration. One item was used to measure interest in collaboration ("The opportunity to collaborate in SSI with faculty in fields other than mine is important to me"). The item was measured on a 1 (disagree) to 8 (agree) scale and indicates the extent to which individuals are interested in interdisciplinary collaboration.

- Perceptions of Credit. We included two items to measure perceptions of credit. Participants were asked to indicate whether they felt as though the university and their departments credited them adequately for their interdisciplinary work $(r=.67, p<.01)$. The items were measured on a 1 (disagree) to 8 (agree) scale and averaged together where higher values indicated that more adequate credit was received.

- Organizational Status. Organizational status was coded according to status $(0=$ non-tenured, 1 = tenured $)$.

\section{Analysis Strategy}

In order to test our mediation hypothesis, we followed procedures outlined by Baron and Kenny (1986), and Preacher and Hayes (2004). First, following Baron and Kenny (1986) we demonstrate that the simple paths between perceived voice and collaboration and perceived voice and advice are both significant. Then we demonstrate through multiple regression that the inclusion of advice and perceived voice as predictors of collaboration removes the relationship between voice and collaboration. Finally, we apply procedures recommended by Preacher and Hayes (2004) using bootstrapping for determining 
the significance of the indirect relationship between perceived voice and collaboration with the inclusion of our mediating variable, advice.

\section{RESULTS 1}

Consistent with hypothesis 1 , the higher participants were in perceived voice, the more collaborative ties they had $\left(R^{2}=.17 ; F(1\right.$, $21)=4.50, p=.04 ; \beta=.42, p=.04)$. Consistent with hypothesis 2 , perceived voice was also positively related to one form of groupserving behavior-advice sharing $\left(R^{2}=.20 ; F(1,21)=5.83, p=.01 ; \beta\right.$ $=.45, p=.03)$. The more voice participants perceived the more they also shared advice with colleagues.

Finally, in support of hypothesis 3 , the relationship between voice and collaborative ties was mediated (Preacher \& Hayes, 2004) by advice sharing (Indirect effect: 5000 bootstrapped samples; Effect = 3.98, Upper $=9.33$ Lower $=.08$ ). That is, the primary reason perceived voice was related to collaboration was due to the degree of advice shared among colleagues. Following Baron and Kenny's (1986) procedures for mediation, including advice sharing in the model examining voice and collaboration reduces the relationship between voice and collaboration to non-significance $(\beta=.14, p=.22)$ however advice remains a significant predictor of collaboration $(\beta=$ $.62, p<.01$ ) (Figure 2).

Also, perceived voice shared only a modestly positive, but nonsignificant relationship with serving on committees $(r=.31, p=.15)$. More importantly, replacing advice sharing with committee membership does not sufficiently explain the relationship between perceived voice and collaboration. In other words, the indirect effect of voice on collaboration through committee membership is not significant $($ Effect $=.003$; Upper $=.02$, Lower $=-.02)$.

\section{Ancillary Analyses}

In addition to testing our theorized relationships, we also examined whether perceived interest in collaboration, or amount of credit received for collaboration efforts, related to collaboration and advice sharing. Results revealed that neither variable related to network measures (see Table 1 for zero-order correlations). Importantly, controlling for these variables in the mediation analyses 
reported above does not change the direction or the significance of the relationship between perceived voice, collaboration, and advice.

FIGURE 2

Mediation Analysis Demonstrating That Degree of Advice Network Mediates the Relationship between Perceived Voice and Degree of Collaboration

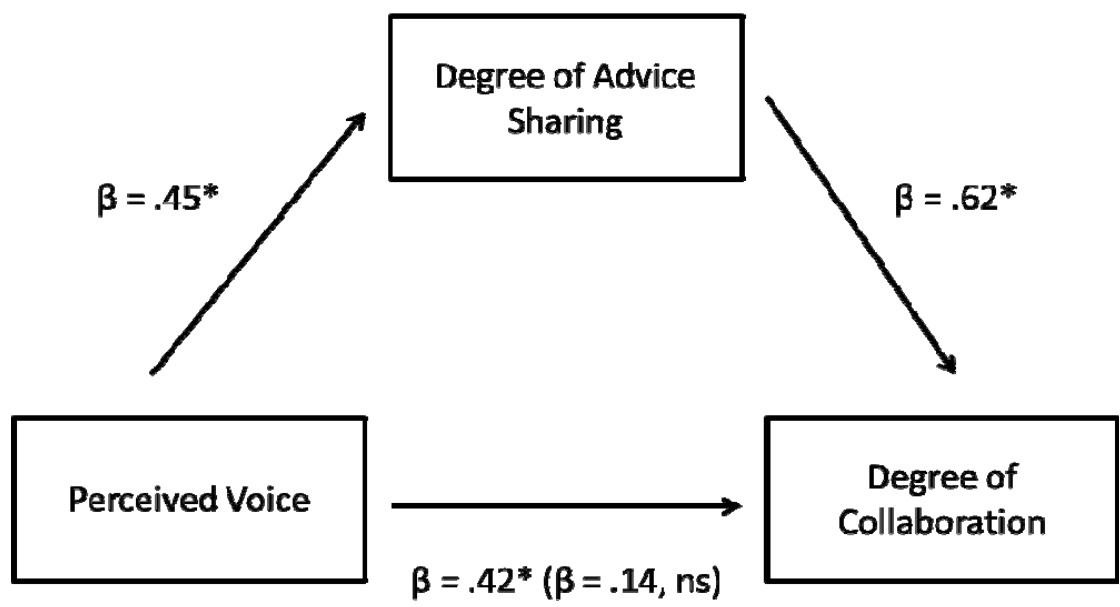

TABLE 1

Zero-Order Correlations among Study Variables

\begin{tabular}{|l|c|c|c|c|c|c|}
\hline \multicolumn{1}{|c|}{ Variables } & 1 & 2 & 3 & 4 & 5 & 6 \\
\hline Survey Items & $\ldots$ & & & & & \\
\hline 1. Voice & .20 & $\ldots$ & & & & \\
\hline 2. Interest & .20 & .15 & $\ldots$ & & & \\
\hline 3. Credit & $.42^{*}$ & -.13 & .28 & $\ldots$ & & \\
\hline Networks & $.45^{*}$ & .01 & .24 & $.68^{* *}$ & $\ldots$ & \\
\hline 4. Collaboration & .31 & $-.37^{\dagger}$ & -.06 & $.42^{*}$ & .13 & $\ldots$ \\
\hline 5. Advice & 5.52 & 6.78 & 4.08 & & & \\
\hline 6. Committee & 1.23 & .80 & 1.31 & & & \\
\hline Mean
\end{tabular}

Note: $t p<.10 ; * p<.05 ; * * p<.01$. 
Because it may also be argued that perceptions of voice are directly the result of one's organizational position, we also examined the role of organizational status. Interestingly, organizational status was unrelated to perceived voice, collaboration, or advice (all t's $<1.05 \mid$, p's $>$.30). Moreover, controlling for organizational status in the analyses examining the relationships between perceived voice, collaboration, and advice does not change the direction or the significance of the reported effects.

\section{DISCUSSION}

In the present research, we tested predictions derived from a group-value model of procedural justice (Lind \& Tyler, 1988) by examining the consequences of perceived voice for the group-serving behavior of advice sharing and their combined effects on interdisciplinary collaboration. Consistent with predictions, we found that perceived voice was significantly and positively related to both advice and collaboration network density. Importantly, and consistent with hypotheses, we found that the reason perceived voice is related to collaboration is because of its relationship with advice sharing. In other words, our research supports that more perceived voice facilitates greater advice sharing which ultimately leads to greater interdisciplinary collaboration. We also demonstrate that the relationship between perceived voice and collaboration is uniquely explained via advice sharing and not another type of group-serving behavior (i.e. serving on committees). Moreover, despite the assumption that other perceptual variables such as interest in collaboration and receiving credit for collaborative activities have been argued to be important for collaboration, they are not in our present study. Even after controlling for other possible explanations (i.e. rank and perceived clarity), perceived voice remained uniquely related to both collaboration and advice sharing.

\section{Implications}

Our findings have important practical and theoretical implications for the study of interdisciplinary collaboration. For starters, this work represents the first quantitative investigation linking voice to interdisciplinary collaboration in an academic organization. Although many have recognized the likely importance of voice in collaborative processes (e.g. Rank, Pace \& Frese, 2004; Franco et al., 2007) no 
empirical research to our knowledge has examined the consequences of voice in facilitating collaboration within organizations. By incorporating a group-value perspective, we support the idea that people form collaborations because perceived voice increases advice sharing among colleagues. This is important because it demonstrates that perceived voice fosters greater substantive collaborations by influencing the degree of information shared among colleagues. Given the current influx of interdisciplinary initiatives on university campuses nationwide (National Research Council, 2004), this research suggests that it may be important to consider more formally supporting perceived voice and advice sharing as a means of improving the extent to which researchers take advantage of collaborative opportunities.

Because the hypotheses of the present research were derived from a group-value model of procedural justice (Lind \& Tyler, 1988) and results support these predictions, this work also has implications for the voice literature. Traditionally, work applying the group-value perspective has examined the impact of voice on group-serving behaviors (Tyler et al., 1996; Barry \& Tyler, 2009) as though they were parallel with other voice effects. The present research opens up the possibility that because perceived voice impacts group-serving behaviors, some of these group-serving behaviors may be the reason voice is related to other organizational outcomes, such as positive feelings towards co-workers (Cornelis, Van Hiel \& De Cremer, 2006), reductions in stress (Brotheridge, 2003), or improved performance (e.g. Hunton, 1996; Libby, 2003). For example, if greater voice encourages greater helping among co-workers (Tyler et al., 1996), then co-workers may also be more likely to provide social support to one another leading to reductions in stress (e.g. Cohen \& Wills, 1985; Cosley, McCoy, Saslow, \& Epel, 2010; Lepore, Allen, \& Evan, 1993; Thorsteinsson \& James, 1999). No studies to our knowledge have examined the mediating effects of group-serving behaviors brought on by voice for other organizational outcomes. Therefore, the current research extends work on the group-value model of procedural justice by identifying a path through which voice can lead to other unintended outcomes like interdisciplinary collaboration via its effect on group-serving behaviors.

By employing existing theories of organizational behavior to better understand collaboration, this research contributes to a growing area 
of research known as the science of team science (Stokols, Hall, Taylor, \& Moser, 2008). Prior to the formal development of this field, much of the empirical work on collaboration had progressed in a correlational, exploratory fashion (e.g. Mellin \& Winton, 2003; Tompkins et al., 1989). By conceptualizing interdisciplinary collaboration as a type of organizational behavior and applying the group-value model of voice (Lind \& Tyler, 1988), we also shed more theoretical context onto our understanding of interdisciplinary collaboration. One fruitful avenue for future research will be to examine the conditions under which perceived voice and advice sharing do not lead to more substantive collaborations. For example, if voice can be differentiated according to whether employees speak out versus speak up, as recent research suggests (Liu, Zhu \& Yang, 2010), then we may expect to find that only "speaking out" forms of voice encourage greater information share and collaboration. Because speaking out focuses voice behavior on colleagues as opposed to supervisors, perceiving that one has more influence over decisions made by colleagues may encourage one to share more with colleagues thereby leading to more collaborations. Alternatively, focusing only on supervisors may not encourage more collaboration. In the present work environment, it is very likely that decisions were made as a group and among colleagues rather than supervisors directing the entire process. Thus, we may be seeing the unique effect of voice as it pertains to speaking out to colleagues rather than voice that is based more on influencing supervisors. Interesting as it may be, without any clear test of this distinction our speculation remains an important avenue for future research.

\section{Limitations and Future Directions}

Aside from potential future directions derived from the theoretical contribution made by the present work, there are also important limitations out of the current research that should be addressed in future studies. First, because we sought to examine real-world collaborative ties in an ongoing and dynamic research setting, we cannot infer causal relationships from these data alone. Thus, future research should examine how manipulations of advice sharing that arise out of perceived voice can facilitate interdisciplinary collaboration. The fact that our data are correlational however should not trump the importance of the present work. Because we were able to assess real work relationships using two different types of data 
(self-report and network) the present research maintains strong external validity.

Another fruitful avenue for future research is to examine the change in collaborative networks over time. Social networks are not static entities but rather dynamic and prone to change over time (e.g. Aboelela, Merrill, Carley, \& Larson, 2007; Haines, Godley, \& Hawe, 2011). Examining how voice influences this change process is essential for understanding how advice networks and collaborations unfold, develop, and dissolve. For example, future research should examine how factors that have previously been shown to facilitate voice impact change in voice and ultimately the change in advice and collaborative relationships. To this end, previous research highlighting the role of leaders (Rank, Pace \& Frese, 2004) and self-efficacy (Avery, 2003; Morrison \& Phelps, 1999) in facilitating voice may also play a crucial role in understanding the dynamics of interdisciplinary collaborations over time. That is, different leadership styles may lead to different expressions of group-serving behaviors and thus may ultimately have different effects on collaboration. In one of the few social network studies on interdisciplinary collaboration, Haines and colleagues (2011) examined structural differences in a variety of collaborative networks (e.g. co-taught, worked on research) in an interdisciplinary group. The primary findings revealed greater density of collaboration in most of the networks and a decrease in the extent to which the networks were centralized around just a few individuals over time. In other words, individuals collaborated more and with a greater variety of people over time. It may be the case that perceived voice and advice sharing are the reason collaboration networks evolve in this way over time. As the present research initiative continues to grow and evolve over time, we continue to monitor these longitudinal changes in the collaboration networks.

Finally, it is important to note that the sample size in the present project was relatively small. Although we examined a nearly complete social network and were sensitive to the fact that interdisciplinary collaborations are often characterized as small groups, it is important to note that these findings may be specific to academic faculty working on an interdisciplinary program and may not generalize to other types of organizations seeking collaboration. However, given the importance of interdisciplinary collaboration in academia today, the findings from the present work should not be trivialized merely 
generalized with caution. Future analyses related to the present project will attempt to capture the change in dynamics as the participants involved in the present research initiative grow in number.

\section{CONCLUSION}

In sum, the present findings have important consequences for both the voice and collaboration literatures, as well as practical relevance to the many interdisciplinary initiatives that are currently developing in academic organizational culture. The present work supports the notion that organizational leaders should emphasize the role of voice by developing programs to increase the opportunities researchers have to influence the decision outcomes associated with these research initiatives. In doing so, these strategies should ultimately improve the amount of unique advice colleagues share with one another, and thus lead to more substantive forms of collaboration. Ultimately, voice may be one way through which we can build greater collaborations that help us to cross the uncertainty separating our disciplines.

\section{ACKNOWLEDGEMENTS}

This work was supported by National Science Foundation award EPS-0904155 to Maine EPSCoR at the University of Maine. We would like to thank James Duffy for his comments on earlier versions of this manuscript. We would also like to thank the research assistants in our labs at the University of South Carolina Beaufort and the University of Maine.

\section{NOTES}

1. Because our network data violate assumptions of independence and thus create potential problems for traditional significance tests, we test the significance of relationships in our regression models using permutation tests (Anderson \& Legendre, 1999). This regression procedure involves basic linear multiple regression by ordinary least squares (OLS), however standard errors and significance are estimated using the random permutations method for creating sampling distributions of $\mathrm{R}$ squared and regression coefficients. 


\section{REFERENCES}

Aboelela, S.W., Merrill, J.A., Carley, K.M., \& Larson, E. (2007). “Social Network Analysis to Evaluate an Interdisciplinary Research Center." Journal of Research Administration, 38(1): 61-78.

Adamson, B., \& Walker, E. (2011). “Messy Collaboration: Learning from a Learning Study." Teaching and Teacher Education, 27(1): 29-36.

Aldrich, H., \& Ruef, M. (2006). Organizations Evolving (2 ${ }^{\text {nd }}$ ed.). Thousand Oaks, CA: Sage.

Anderson, M. J., \& Legendre, P. (1999). “An Empirical Comparison of Permutation Methods for Tests of Partial Regression Coefficients in a Linear Model." Journal of Statistical Computation and Simulation, 62(3): 271-303.

Argote, L., \& Ingram, P. (2000). "Knowledge Transfer: A Basis for Competitive Advantage in Firms." Organizational Behavior and Decision Processes, 82(1): 150-169.

Avery, D.R., McKay, P.F., Wilson, D.C., Volpone, S.D., \& Killham, E.A. (2011). "Does Voice Go Flat? How Tenure Diminishes The Impact of Voice." Human Resource Management, 50(1): 147-158.

Avery, D.R., \& Quinones, M.A. (2002). "Disentangling the Effects of Voice: The Incremental Roles of Opportunity, Behavior, and Instrumentality in Predicting Procedural Fairness." Journal of Applied Psychology, 87(1): 81-86.

Avery, D.R. (2003). "Personality as a Predictor of the Value of Voice." Journal of Psychology: Interdisciplinary and Applied, 137(5): 435446.

Baron, R.M., \& Kenny, D.A. (1986). "The Moderator-Mediator Variable Distinction in Social Psychological Research: Conceptual, Strategic, and Statistical Considerations." Journal of Personality and Social Psychology, 51(6): 1173-1182.

Barry, H., \& Tyler, T.R. (2009). "The Other Side of Injustice: When Unfair Procedures Increase Group-Serving Behavior." Psychological Science, 20(8): 1026-1032. 
Bennett, N., \& Kidwell, R.E. (2001). "The Provision of Effort in SelfDesigning Work Groups: The Case of Collaborative Research." Small Group Research, 32(6): 727-744.

Boix Mansilla, V.B., \& Duraising, E.D. (2007). “Targeted Assessment of Students' Interdisciplinary Work: An Empirically Grounded Framework Proposed." Journal of Higher Education, 78(2): 215237.

Borgatti, S.P., \& Cross, R. (2003). "A Relational View of Information Seeking and Learning in Social Networks." Management Science, 49(4): 432-445.

Borman, W.C., \& Motowidlo, S.J. (1997). "Task Performance and Contextual Performance: The Meaning for Personnel Selection Research." Human Performance, 10(2): 99-109.

Brotheridge, C.M. (2003). "The Role of Fairness in Mediating the Effects of Voice and Justification on Stress and Other Outcomes in a Climate of Organizational Change." International Journal of Stress Management, 10(3): 253-268.

Cohen, S., \& Wills, T.A. (1988). "Stress, Social Support, and the Buffering Hypothesis." Psychological Bulletin, 98(2): 310-357.

Conchie, S.M., Taylor, P.J., \& Donald, I.J. (2012). “Promoting Safety Voice with Safety-Specific Transformational Leadership: The Mediating Role of Two Dimensions of Trust." Journal of Occupational Health Psychology, 17(1): 105-115.

Cornelis, I., Van Hiel, A., \& De Cremer, D. (2006). "Effects of Procedural Fairness and Leader Support on Interpersonal Relationships among Group Members." Group Dynamics: Theory, Research, and Practice, 10(4): 309-328.

Cosley, B. J., McCoy, S. K., Saslow, L. R., \& Epel, E. S. (2010). "Is Compassion for Others Stress Buffering? Consequences of Compassion and Social Support for Physiological Reactivity to Stress." Journal of Experimental Social Psychology, 46(5): 816823.

Cummings, J., \& Kiesler, S. (2005). "Collaborative Research across Disciplinary and Organizational Boundaries." Social Studies of Science, 35(5): 703-722. 
Ewel, K.C. (2004). "Natural Resource Management: The Need for Interdisciplinary Collaboration." Ecosystems, 4(8): 716-722.

Folger, R. (1977). "Distributive And Procedural Justice: Combined Impact of Voice and Improvement on Experienced Inequality." Journal of Personality and Social Psychology, 35(2): 108-119.

Franco, L.M., McKay, M., Miranda, A., Chambers, N., Paulino, A., \& Lawrence, R. (2007). "Voices from the Community: Key Ingredients for Community Collaboration." Social Work in Mental Health, 5(3-4): 313-331.

Freeman, L.C. (1979). "Centrality in Social Networks: Conceptual Clarification." Social Networks, 1(3): 223-258.

Hackett, E.J. (2005). “Essential Tensions: Identity, Control, and Risk in Research." Social Studies of Science, 35(5): 787-826.

Hackett, E.J. (1990). "Science as a Vocation in the 1990s: The Changing Organizational Culture of Academic Science." Journal of Higher Education, 61(3): 241-279.

Hagstrom, W. (1965). The Scientific Community. New York: Basic Books.

Haines, V.A., Godley, J., \& Hawe, P. (2011). "Understanding Interdisciplinary Collaborations as Social Networks." American Journal of Community Psychology, 47(1-2): 1-11.

Holley, K.A. (2009). "Interdisciplinary Strategies as Transformative Change in Higher Education." Innovative Higher Education, 34(5): 331-344.

Hunton, J. E. (1996). “Involving Information System Users in Defining System Requirements: The Influence of Procedural Justice Perceptions on User Attitudes and Performance." Decision Sciences, 27(4): 647-671.

Knoke, D., \& Yang, S. (2008). Social Network Analysis (2 ed.). Thousand Oaks, CA: Sage Publications.

Konovsky, M.A., \& Folger, R. (1991). "The Effects of Procedures, Social Accounts, and Benefits Level on Victims' Layoff Reaction." Journal of Applied Social Psychology, 21(8): 630-650.

LePine, J.A., \& Van Dyne, L. (2001). "Voice and Cooperative Behavior as Contrasting Forms of Contextual Performance: Evidence of 
COLLABORATIVE VOICE: EXAMINING THE ROLE OF VOICE IN INTERDISCIPLINARY COLLABORATION 159

Differential Relationships with Big Five Personality Characteristics." Journal of Applied Psychology, 86(2): 326-336.

Lepore, S.J., Allen, K.A., \& Evan, G.W. (1993). "Social Support Lowers Cardiovascular Reactivity to an Acute Stressor." Psychosomatic Medicine, 55(6): 518-524.

Libby, T. (2003). "The Effect of Fairness in Contracting on the Creation of Budgetary Slack." Advances in Accounting Behavioral Research, 6: 145-169.

Lind, E.A., \& Tyler, T.R. (1988). The Social Psychology of Procedural Justice. New York: Plenum Press.

Lind, E. A., Kanfer, R., \& Earley, P. C. (1990). "Voice, Control, and Procedural Justice: Instrumental and Noninstrumental Concerns in Fairness Judgments." Journal of Personality and Social Psychology, 59(5): 952-959.

Liu, W., Zhu, R., \& Yang, Y. (2010). “I Warn You Because I Like You: Voice Behavior, Employee Identifications, and Transformational Leadership." The Leadership Quarterly, 21(1): 189-202.

Lopes, L.L. (1987). "Between Hope and Fear: The Psychology of Risk." Advances in Social Psychology, 20(3): 255-295.

McFarlin, D.B., \& Sweeney, P.D. (1992). “Distributive and Procedural Justice as Predictors of Satisfaction with Personal and Organizational Outcomes." Academy of Management Journal, 35(3): 626-37.

Mellin, A.E., \& Winton, P.J. (2003). "Interdisciplinary Collaboration among Early Intervention Faculty Members." Journal of Early Intervention, 25(3): 173-188.

Merton, R.K. (1973). The Sociology of Science. Chicago, IL: University of Chicago Press.

Moorman, R.H. (1991). "Relationship Between Organizational Justice and Organizational Citizenship Behaviors: Do Fairness Perceptions Influence Employee Citizenship?" Journal of Applied Psychology, 76(6): 845-855.

Morrison, E.W., \& Phelps, C.C. (1999). "Taking Charge at Work: Extrarole Efforts to Initiate Workplace Change." The Academy of Management Journal, 42(4): 403-419. 
National Research Council (2004). Facilitating Interdisciplinary Research. Washington, DC: The National Academies Press.

Newell, W. (2001). "A Theory of Interdisciplinary Studies." Issues in Integrative Studies, 19: 1-15.

Ng, T.W.H., \& Feldman, D.C. (2012). "Employee Voice Behavior: A Meta-Analytic Test of the Conservation of Resources Framework." Journal of Organizational Behavior, 33(2): 216-234.

Organ, D.W. (1988). Organizational Citizenship Behavior: The Good Soldier Syndrome. Lexington, MA: Lexington Books

Organ, D.W. (1997). “Organizational Citizenship Behavior: It's Construct Clean-up Time." Human Performance, 10(2): 85-97.

O'Reilly, C.A., \& Chatman, J. (1986). “Organizational Commitment and Psychological Attachment: The Effects of Compliance, Identification, and Internalization on Prosocial Behavior." Journal of Applied Psychology, 71(3): 492-499.

Ozer, M. (2011). “A Moderated Mediation Model of the Relationship between Organizational Citizenship Behavior and Job Performance." Journal of Applied Psychology, 96(6): 1328-1336.

Preacher, K.J., \& Hayes, A.F. (2004). "SPSS and SAS Procedures for Estimating Indirect Effects in Simple Mediation Models." Behavior Research Methods, Instruments, \& Computers, 36(4): 717-731.

Rank, J., Pace, V.L., \& Frese, M. (2004). "Three Avenues for Future Research on Creativity, Innovation, and Initiative." Applied Psychology: An International Review, 53(4): 518-528.

Schein, E. (1972). Professional Education. New York: McGraw-Hill Book Co.

Slatin, C., Galizzi, M., Melillo, K.D., \& Mawn, B. (2004). “Conducting Interdisciplinary Research to Promote Healthy and Safe Employment in Health Care: Promises and Pitfalls." Public Health Reports, 119(1): 60-72.

Smith, H. J., \& Tyler, T.R. (1997). "Choosing the Right Pond: The Impact of Group Membership on Self-Esteem and Group-Oriented Behavior." Journal of Experimental Social Psychology, 33(2): 146 $-170$. 
COLLABORATIVE VOICE: EXAMINING THE ROLE OF VOICE IN INTERDISCIPLINARY COLLABORATION 161

Stokols, D., Hall, K.L., Taylor, B.K., \& Moser, R.P. (2008). “The Science of Team Science: Overview of the Field and Introduction to the Supplement." American Journal of Preventive Medicine, 35(2): S77-S89.

Tajfel, H., \& Turner, J. (1986). "The Social Identity Theory of Intergroup Behavior." In S. Worchel (Ed.), Psychology of Intergroup relations (pp. 33-47). Chicago, IL: Nelson-Hall.

Thibaut, J., \& Walker, L. (1975). Procedural Justice: A Psychological Analysis. Hillsdale, NJ: Erlbaum.

Thorsteinsson, E. B., \& James, J. E. (1999). "A Meta-Analysis of the Effects of Experimental Manipulations of Social Support during Laboratory Stress." Psychology and Health, 14(5): 869-886.

Tompkins, F.M., Weaver, R., \& Landers, M.F. (1989). "The Identification of Factors Which Influence Interdisciplinary Collaboration within Educational Settings." Paper Presented at the Annual Meeting of the American Educational Research Association, San Francisco, CA, March 27-31.

Travis, D., \& Mor Barak, M. (2010). "Fight or Flight? Factors Influencing Child Welfare Workers' Propensity to Seek Positive Change or Disengage From Their Jobs." Journal of Social Service Research, 36(3): 188-205.

Traweek, S. (1988). Beamtimes and Lifetimes: The World of High Energy Physics. Cambridge, MA: Harvard University Press.

Tyler, T., Degoey, P., \& Smith, H. (1996). “Understanding Why the Justice of Group Procedures Matters: A Test of the Psychological Dynamics of the Group-Value Model." Journal of Personality and Social Psychology, 70(5): 913-930.

Tyler, T.R., Rasinski, K., \& Spodick, N. (1985). "The Influence of Voice on Satisfaction with Leaders: Exploring the Meaning of Process Control." Journal of Personality and Social Psychology, 48(1): 7281.

Van Den Bos, K. (2001). “Uncertainty Management: The Influence of Uncertainty Salience on Reactions to Perceived Procedural Fairness." Journal of Personality and Social Psychology, 80(6): 931-941. 
Wasserman, S., \& Faust, K. (1996). Social Network Analysis. Cambridge, MA: Cambridge University Press.

Zagenczyk, T.J., \& Murrell, A.J. (2009). "It Is Better to Receive Than to Give: Advice Network Effects on Job and Work-Unit Attachment." Journal of Business and Psychology, 24(2): 139-152.

Zhang, Z., \& Peterson, S.J. (2011). "Advice Networks in Teams: The Role of Transformational Leadership and Members' Core SelfEvaluations." Journal of Applied Psychology, 96(5): 1004-1017.

Zare, R.N. (1997). "Knowledge and Distributed Intelligence." Science 275 (5303): 1047. 